NBER WORKING PAPER SERIES

\title{
THE TRANSMISSION OF WOMEN'S FERTILITY, HUMAN CAPITAL AND WORK ORIENTATION ACROSS IMMIGRANT GENERATIONS
}

\author{
Francine D. Blau \\ Lawrence M. Kahn \\ Albert Yung-Hsu Liu \\ Kerry L. Papps \\ Working Paper 14388 \\ http://www.nber.org/papers/w14388 \\ NATIONAL BUREAU OF ECONOMIC RESEARCH \\ 1050 Massachusetts Avenue \\ Cambridge, MA 02138 \\ October 2008
}

\begin{abstract}
We are indebted for helpful comments and suggestions to Susan Dynarski, Klaus Zimmermann, two anonymous referees and participants at the Society of Labor Economists meetings in Boston, May 2009; the Midwest Economics Association Meetings in St Louis, March 2011; the Centre of Equality, Social Organization, and Performance (ESOP) Workshop on Gender and Households in Oslo, May 2011; the IZA/CEPR 13th European Summer Symposium in Labour Economics in Buch, Ammersee, September 2011; and seminars at the Institute for the Study of Labor (IZA) and Yale Law School. We thank Peter Brummund for excellent research assistance, and the Russell Sage Foundation for financial support. Portions of the research for this paper were completed while Blau and Kahn were Visiting Fellows in the Economics Department of Princeton University, supported by the Industrial Relations Section. The views expressed herein are those of the author(s) and do not necessarily reflect the views of the National Bureau of Economic Research.
\end{abstract}

NBER working papers are circulated for discussion and comment purposes. They have not been peerreviewed or been subject to the review by the NBER Board of Directors that accompanies official NBER publications.

(C) 2008 by Francine D. Blau, Lawrence M. Kahn, Albert Yung-Hsu Liu, and Kerry L. Papps. All rights reserved. Short sections of text, not to exceed two paragraphs, may be quoted without explicit permission provided that full credit, including (C) notice, is given to the source. 
The Transmission of Women's Fertility, Human Capital and Work Orientation Across Immigrant Generations

Francine D. Blau, Lawrence M. Kahn, Albert Yung-Hsu Liu, and Kerry L. Papps

NBER Working Paper No. 14388

October 2008, Revised January 2012

JEL No. J1,J16,J22,J24,J61

\section{ABSTRACT}

Using 1995-2011 Current Population Survey and 1970-2000 Census data, we find that the fertility, education and labor supply of second generation women (US-born women with at least one foreign-born parent) are significantly positively affected by the immigrant generation's levels of these variables, with the effect of the fertility and labor supply of women from the mother's source country generally larger than that of women from the father's source country and the effect of the education of men from the father's source country larger than that of women from the mother's source country. We present some evidence that suggests our findings for fertility and labor supply are due to at least in part to intergenerational transmission of gender roles. Transmission rates for immigrant fertility and labor supply between generations are higher than for education, but there is considerable intergenerational assimilation toward native levels for all three of these outcomes.

Francine D. Blau

ILR School

Cornell University

268 Ives Hall

Ithaca, New York 14853-3901

and NBER

fdb4@cornell.edu

Lawrence M. Kahn

ILR School

Cornell University

258 Ives Hall

Ithaca, NY 14853

lmk12@cornell.edu
Albert Yung-Hsu Liu

Mathematica Policy Research, Inc.

505 14th St., Suite 800

Oakland, CA 94612-1475

aliu@mathematica-mpr.com

Kerry L. Papps

Department of Economics

University of Bath

Bath, BA2 7AY

UNITED KINGDOM

k.1.papps@bath.ac.uk 


\section{Introduction}

A steady flow of new immigration has resulted in an increase in the foreign-born share of the US population from 4.8 percent in 1970 to 12.5 percent in 2009. Perhaps more dramatically, the composition of the foreign-born population has changed markedly. In 1970, 70.4 percent of the foreign born came from Europe or North America; by 2009, 80.8 percent were from Asia and Latin America (US Bureau of the Census: http://www.census.gov). An additional feature of this shift that is less frequently noted is that the immigrant population increasingly comes from countries with a more traditional division of labor by gender (i.e., relatively lower female participation rates) than the United States, and this tends to be reflected in their US labor supply behavior (Antecol 2000; Blau, Kahn and Papps 2011; Blau and Kahn 2011). Immigrant women also tend to have more children than native-born women, mirroring their countries of origin (Blau 1992), although the immigrant-native difference has declined among the most recent immigrants as fertility levels have fallen around the world (Blau, Kahn and Papps 2011). As the share of the US population that is foreign born has risen, an increasing fraction of the population consists of second generation immigrants—native-born individuals with at least one foreign-born parent. $^{1}$

These trends highlight the fact that the assimilation process of immigrants has an important intergenerational component. If a traditional division of labor by gender among immigrants is transmitted to their children, the growing immigrant share in the population and the shift toward a more traditional division of labor among immigrants (relative to natives) can have substantial effects on the future labor supply and fertility behavior of women born in the

\footnotetext{
${ }^{1}$ In 1990, 13 percent of U.S. children (ages 0-17) had at least one immigrant parent; this had increased to nearly one quarter (23 percent) by 2008 (Fortuny 2010).
} 
United States. Alternatively, however, the children of immigrants may assimilate toward native levels of labor supply and fertility as they become acculturated to work and family size norms in the United States or as they respond to labor market opportunities here. If so, the current immigrant-native gaps in these outcomes will not have large long-term effects.

In this paper, we use data on second-generation women from the March Current Population Surveys (CPS) from 1995 to 2011 linked to data on immigrants in the parental generation from the 1970, 1980, 1990, and 2000 Censuses to study the transmission of firstgeneration immigrants' education, fertility, and labor supply to second-generation women. We focus particularly on women's labor supply and fertility due to the salience of the gender role issue and the smaller amount of previous research on this subject. The study of the intergenerational transmission of values and behavior among immigrants is also relevant to a broader literature examining the impact of "culture," or preferences and beliefs developed in a different time or place on current economic behavior (Fernández 2008).

Our research design estimates the outcome of three related processes. First, immigrant parents, like parents in general, may directly pass on their own characteristics and behavioral traits to their children. Second, they may pass on their ethnic or cultural characteristics. Third, both these effects may be moderated as immigrants and their descendants experience some level of assimilation toward US native behavior. While we cannot distinguish between these three types of effects, it might be argued that their combined effect is the most relevant "bottom line" assessment of the extent of intergenerational transmission.

Unlike earlier work on the descendants of immigrants, we examine the impact of the characteristics of both mothers and fathers in the immigrant generation on second generation women. We also investigate differences across "family types," that is second generation women 
who had two foreign born parents, only a foreign-born mother, and only a foreign-born father. This disaggregation, made possible by the richness of the CPS data, potentially yields a richer set of hypothesis tests about culture and assimilation than more aggregated approaches. For example, data on women from the mother's source country may proxy for both the effects of mothers as role models and source country culture, while, controlling for the effect of mother's parental characteristics, data on women from the father's source country may reflect the incremental effect of source country culture. With regard to family type, it may be that coming from a family with two immigrant parents represents a larger "treatment" than coming from a family with only one.

\section{Relationship to Previous Literature and Contribution of the Study}

Our analysis builds on some recent papers that have studied the impact of source country or parental characteristics on the education, fertility or labor supply of immigrants' descendants in the United States. Using 1970 Census data on US-born women with foreign-born fathers, Fernández and Fogli (2009) found that source country female labor supply and fertility each had a positive effect on the corresponding outcome of second-generation women. Two other studies have found evidence of positive effect of source country labor force participation (Antecol 2000) and fertility (Fernández and Fogli 2006) on the these outcomes for US-born women based on the respondent’s self-reported ancestry. Finally, using 1994-2003 CPS data, Blau and Kahn (2007) found that current Mexican immigrant women had far lower levels of schooling and labor supply, as well as higher fertility levels, than native non-Hispanic whites. However, gaps were 
much smaller in the second-generation, suggesting assimilation but also some persistence. ${ }^{2}$

Also relevant to our work are two papers that study intergenerational transmission using a similar methodology to ours, although neither explicitly examined gender roles. First, Borjas (1993) found evidence of intergenerational transmission correlating the wages of 1940 immigrant generation fathers with second-generation sons in the 1970 Census. Card, DiNardo and Estes (2000) expanded on these findings, examining the intergenerational transmission of earnings, education and marital assimilation, for two cohorts of second generation respondents (identified as individuals with foreign-born fathers) matched to characteristics of their immigrant fathers in earlier Censuses. The second-generation from the 1970 Census was matched to 1940 data on immigrant men; and the second-generation from the 1994-1996 CPS was matched to 1970 Census data on immigrant men. The authors found that there was significant intergenerational transmission of education and wages, with a roughly similar rate of intergenerational transmission for each cohort.

We contribute to the literature on gender and intergenerational transmission of immigrant behavior in several ways. First, as discussed above, the CPS has information on the country-ofbirth of both parents, permitting us to gauge the relative importance of the characteristics of immigrant mothers versus immigrant women from the fathers' source country, as well as the strength of intergenerational transmission for individuals with two foreign-born parents compared to those with only one. In contrast, Card, DiNardo, and Estes (2000), Borjas (1993), and Fernández and Fogli (2009) are only able to match second-generation individuals with their

\footnotetext{
${ }^{2}$ In a recent paper, Alesina, Giuliano and Nunn (2011) test the hypothesis that traditional agricultural practices, namely the utilization of plough agriculture, influenced the development of this culture across societies. In one application they find evidence of cultural transmission, based on the use of the plough in the source country, for second-generation immigrants in the United States.
} 
fathers, due to the incomplete Census data on the birthplace of foreign-born mothers. ${ }^{3}$ In addition to being unable to examine the differential effect of immigrant mothers compared to fathers on the second generation, work that uses data only on the respondent's father misses about one quarter of the second generation sample (Table A1). If gender role transmission from mother to daughter is especially strong, this omission could be particularly important for a study of the transmission of gender roles. The CPS information on the actual birthplaces of the respondent's parents is also an improvement on the data on self-reported ancestry of US-born respondents used by Antecol (2000) and Fernández and Fogli (2006). Data on self-reported ancestry are less precise in that they include information on second and higher order generations. Further, Duncan and Trejo’s (2007) study of Mexican-Americans suggests that the more successfully-assimilated native born are less likely to report a foreign ancestry.

Our comparison of the impact of mother's and father's country-of-birth also contributes to the literature on intergenerational transmission of immigrant education, where previous results have been mixed. Gang and Zimmermann (2000) find no effect of parental education for second generation immigrants in Germany, ${ }^{4}$ while Van Ours and Veenman (2003) and Bauer and Riphahn (2007) find that mother's and father’s education had similar effects on second generation individuals' educational attainment in the Netherlands and Switzerland, respectively. In contrast, studies of the general issue of intergenerational transmission of education usually find larger effects for fathers than mothers (for a review, see Pronzato 2012).

Second, while Fernández and Fogli (2009) also looked at the second generation, they focused on the impact of source country characteristics on the behavior of second generation

\footnotetext{
${ }^{3}$ When both parents were foreign-born, the 1970 Census reported only the father's country of birth. While Card, DiNardo and Estes (2000) used the same CPS data we do for their recent cohort (although for fewer years), they used information only on the father's country of birth in order to make their analysis of 1970 to 1994-1996 assimilation consistent with their 1940 to 1970 analysis.

${ }^{4}$ However, Gang and Zimmerman found that parental education did matter for native-born Germans and that fathers' education had a larger effect than mothers'.
} 
immigrants. In contrast, we examine the process by which source country culture gets transmitted to future generations in the host country by looking explicitly at intergenerational transmission from immigrants to their children born in the United States, although we also examine the impact of source country characteristics. One of the purposes of our paper is to shed light on the rate of assimilation across generations and we provide estimates of transmission rates. In addition, our current data on the second generation from the 1995-2011 CPS provides an updated consideration of the issues of gender and culture compared to the 1970 Census data employed by Fernández and Fogli (2009). (The 1970 Census was the last Census to collect data on foreign parentage.) Since 1970, there have been considerable changes in the composition of immigrant parents by source country, as well as in aggregate female labor force participation and fertility rates in the United States that might affect the findings. Gender roles in the 1990s and 2000s were considerably different from what they were in 1970, with far higher levels of female labor force participation now, as well as lower fertility rates (Blau, Ferber and Winkler 2010). And, as mentioned earlier, immigration to the United States has shifted from being a largely North American and European phenomenon to a largely Asian and Latin American one. Further, there is a growing gap between the labor supply of US-born and immigrant women today than in earlier years (Blau, Kahn and Papps 2011). Thus, the process of assimilation of second generation women into the US labor market may very well have changed since 1970.

Third, we include three tests of intergenerational transmission that may shed light on the potential role of the intergenerational transmission of gender roles compared to other unobservables. In the first test, we estimate our basic models for second-generation men. An effect of immigrant women's labor supply behavior that is unique to or stronger for secondgeneration women than men suggests that the effect for women reflects parental or cultural 
gender roles rather than other unmeasured factors that may be expected to have a similar effect for both men and women. ${ }^{5}$ Of particular interest is that we may contrast our finding for female and male transmission for labor supply, a potentially gender-linked variable, to those for education, a plausibly more gender neutral variable. (We are not able to meaningfully examine fertility for men in our data sets because it is measured by number of children present, and women generally retain custody of children when a marriage breaks up or children are born out of wedlock.) Second, we expand our basic specification, which controls only for parental generation characteristics and respondent's age (as well as CPS survey year), to include controls for other individual characteristics like education, location and marital status (this is similar to the specification employed by, e.g. Antecol 2000 and Fernández and Fogli 2009). Our preferred, parsimonious specification excludes these potentially endogenous controls and allows parental generation characteristics to influence respondent's outcomes both directly and indirectly through their effects on respondent's education, location, and marital status. However, finding an effect of parental characteristics even with controls for these individual characteristics provides suggestive evidence that they do affect individuals' preferences. Third, again similar to Antecol 2000 and Fernández and Fogli 2009, we examine the impact of source country characteristics (rather than the characteristics of parental generation immigrants) on second generation behavior. This more directly tests the hypothesis that source country characteristics influence the behavior of second generation immigrants in the United States.

Finally, while our study is methodologically similar to Card, DiNardo and Estes (2000), they did not examine the variables of primary interest here, fertility and labor supply. Moreover, they used a single year to compute parental characteristics, e.g., matching their second

\footnotetext{
${ }^{5}$ In a working paper version of Fernández and Fogli (2009), the authors examined the impact of their source country variables for men's hours worked and presence of children and did not find an effect (see, Fernández and Fogli 2005).
} 
generation CPS sample to immigrants in the 1970 Census. In contrast, we use information on the age of second-generation individuals in the 1995-2011 CPS to match them to the parent generation in the appropriate Census.

\section{Data and Descriptive Patterns}

The 1995-2011 March CPS files comprise our basic data source on second generation women (i.e., US-born women with at least one foreign parent). The CPS sample is restricted to ages 25-49: age 25 was selected to focus on individuals who have generally completed their education; age 49 to focus on individuals still potentially in their prime working years and for whom children present is likely to be a good estimate of fertility. ${ }^{6}$ We match second generation women to their parents' generation by calculating the year the respondent would have been 10 years old, a likely formative age. ${ }^{7}$ We then use 1970-2000 Census data to simulate the immigrant parents' behavior, linearly interpolating across adjacent Censuses if needed; these Census-based outcomes are themselves age-adjusted to age 40 to take into account compositional effects among immigrants (see the Appendix). ${ }^{8}$ (If immigrants from a particular country in a Census year are especially young or old; their current labor supply may not be representative of their lifetime behavior.) We go back only to the 1970 Census in collecting immigrant characteristics because the 1960 Census data are relatively poor for matching source countries compared to later Censuses. Respondents who turn 10 prior to 1970 are matched to the 1970 Census. We are able to construct 69 country groups, far larger than Card, DiNardo and Estes’

\footnotetext{
${ }^{6}$ To the extent that the number of children present differs from fertility-e.g., older children may have left home, our control for age addresses this issue, since older women are more likely than younger women to have had children that are no longer in the household.

${ }^{7}$ Results were similar when we used age 14 .

${ }^{8}$ Card, DiNardo and Estes (2000) also age-adjusted immigrant and second generation outcomes.
} 
(2000) sample of 33 countries. $^{9}$

Table 1 provides some motivation for the study by comparing the outcomes of interest adjusted to age 40 for immigrant and native women in 1980 (when many immigrant parents would have been surveyed) based on Census data, and for immigrant, native, and second generation women in 2000 based on CPS data. ${ }^{10}$ As may be seen, immigrants had a substantial education deficit in 1980 of 1.4 years (11 percent), and also worked 75 (7.3 percent) fewer hours and had on average 0.14 (8.3) percent more children than natives. One motivation for our study is to find out how persistent such differences are across generations. Table 1 shows that, while immigrants’ educational deficit remained roughly constant over time, immigrant-native labor supply and fertility differences increased—to 113 hours (14.3 percent) for hours and 0.2 (15.9 percent) for number of children. Thus, traditional work and family patterns have become more pronounced among immigrants (relative to natives). This highlights the importance of learning the extent to which these patterns will be transmitted by immigrants to their children.

Table 1 also shows that, on average, second generation women currently have very similar levels of schooling, labor supply, and fertility to those of natives with native parents (see also Table A1); in fact, second generation women’s education and labor supply are actually slightly higher and their fertility is slightly lower than those of natives. ${ }^{11}$ Thus, in the aggregate, all of the 1980 immigrant-native differences have been erased in one generation. However, there is considerable variability in education, labor supply and fertility across immigrants and second generation women from different countries. These differences provide us with an opportunity to

\footnotetext{
${ }^{9}$ In addition to having fewer years of the CPS available, Card, DiNardo and Estes were also limited by the need to maintain comparability with the 1940 Census data. Note that, although Puerto Rico is a US territory, it is treated as a foreign birth place for the purposes of our analyses.

${ }^{10}$ In order to make the CPS and Census data comparable, natives are defined as all US-born women regardless of parental birthplace in Table 1. However, the means for natives with native parents for 2000 from the CPS data (results not shown) are virtually identical to the means for all natives for 2000.

${ }^{11}$ Second generation men’s schooling and labor supply levels are also very similar to natives (Table A1).
} 
test the impact of source country culture on the behavior of future generations. Table 2 illustrates this variability by showing data on immigrant and second generation outcomes for three major source regions: (i) Europe and Canada; (ii) Latin America and the Caribbean; and (iii) Asia. ${ }^{12}$ In 1980, immigrants from Europe and Canada were quite similar to natives in their education, fertility and labor supply, while immigrants from Latin America and the Caribbean were a less educated group, with low annual work hours and high fertility, and immigrants from Asia had high levels of education and labor supply (although their fertility is somewhat higher than that of natives). Data on immigrants in 2000 suggest broadly similar differences across immigrant groups. Comparing second generation women in 2000 to immigrants in 1980 to get a rough idea of intergenerational persistence, we see that, while there has been considerable intergenerational assimilation, second generation women from Latin American and the Caribbean still lag behind natives in education and have higher fertility, while second generation women from Asia, like their immigrant parents, are more highly educated and have higher annual hours than natives.

Appendix Table A1 provides further descriptive information for natives with native parents and second-generation women and men. As noted earlier, the incidence of secondgeneration women and men with both parents foreign born is slightly under half, with the remainder divided between mother-only and father-only foreign-born. Thus, previous work which focuses on individuals with foreign-born fathers misses over a quarter (26-27 percent) of second-generation individuals. Among second-generation women and men with both parents foreign-born, the parents come from the same source country in the vast majority (87-88 percent) of the cases. Tabulations of the source countries of the immigrant parents of the second

\footnotetext{
${ }^{12}$ The Middle East, which is located partially in Asia and partially in the Northern Africa, is not included in Asia. With only 578 second generation women from the Middle East we do not include it as a separate region in Table 2.
} 
generation in our 1995-2011 CPS data (results not shown) highlight the shifting composition of the second generation over time. Compared to the 1970 Census data analyzed by Fernández and Fogli (2009), in which 71 percent had fathers born in Europe, this was true of only 30 percent of contemporary second-generation women. ${ }^{13}$

\section{Empirical Procedures and Regression Results}

\section{A. Empirical Procedures}

We analyze intergenerational transmission of fertility, labor supply and education for second-generation women from the 1995-2011 March CPS files by estimating models of the following form:

$$
y_{i t}=B^{\prime} Z_{i t}+\sum_{c} a_{c} X_{c i t}+u_{i t}
$$

where for each individual $i$ in year $t, y$ is an outcome variable including education (years of schooling), fertility (number of children present), or labor supply (annual work hours including zero hours); $Z$ is a vector of controls to be discussed shortly, $X$ is a vector of immigrant parent characteristics with $c$ indexing each characteristic (for example, average labor supply of immigrant women from the mother's country), and $\mathrm{u}$ is a disturbance term.

The vector $X$ includes age-adjusted characteristics of immigrants in the parents' generation, including education (years of schooling) of women from the mother's source country and of men from the father's source country, ${ }^{14}$ and measures of fertility (number of children present) and labor supply (annual hours including zeroes) for women from the mother's source country and women from the father's source country. Fertility and labor supply are included to

\footnotetext{
${ }^{13}$ Fernández and Fogli (2009) excluded women with fathers born in Russia or countries that became centrally planned around World War II, as well as countries with fewer than 15 observations.

14 Beginning in 1994, the CPS coded education in categories, as did the 2000 Census. We mapped these into years of schooling attained by using Jaeger's (1997) suggested algorithm.
} 
measure the effects both of the home environment and cultural gender role attitudes. For this reason we focus on female behavior and include the fertility and labor supply of immigrant women from both the source country of the respondent's mother and the source country of the respondent's father. Labor supply of women, in particular, is perhaps the key indicator of gender roles. In contrast male labor supply is less variable across groups and expected to be less informative about gender roles. We include education of women from the mother's source country and of men from the father's source country as proxies for the home environment and the socio-economic status of the respondent's family. There is a large literature documenting the positive correlation between parental and children's education, with possible causal mechanisms including the effect of parents' education on parental time allocation and parental productivity in activities that enhance child quality, as well as its effect on the socioeconomic status of the family (Black and Devereux 2010). Educational differences in the parental generation may also be correlated with cultural preferences for education..$^{15}$ Our parental education variables broadly measure the impact of such effects.

These six parental characteristics variables are designed to capture the most important and relevant characteristics of the parental immigrant generation. It would be possible to include some additional parental characteristics for immigrants from mothers' and fathers' source countries. However, the very high correlation between the education of women and men from the mother's (father's) source country make it difficult to include additional education variables and obtain meaningful results. ${ }^{16}$ And, as expected, we did not find parental generation male labor supply informative for female labor supply and fertility, but we do discuss some results for

\footnotetext{
${ }^{15}$ Chiswick (1988) and Gang and Zimmerman (2000) postulate that parental cultural differences in preferences may play a role in ethnic differences in outcomes.

${ }^{16}$ Among respondents who have an immigrant mother, the correlation between immigrant men and women from the mother's source country is .98; for respondents with an immigrant father, the comparable correlation is also .98.
} 
specifications including this variable. We note that we already include more controls than is standard in this literature, which has previously focused only on the father's source country and the matching variable-e.g., source country female labor supply in a female labor supply regression (see, Antecol 2000; Fernández and Fogli 2009). ${ }^{17}$

As previously noted, we locate the Census (Censuses) nearest to the time the respondent was age 10, interpolating between Censuses where necessary. Thus, second-generation CPS respondents from the same origin country can have different values for these variables depending on their age: older respondents are matched with immigrants from earlier Censuses. The relevant parental characteristics variables are set to 0 for respondents with a native-born mother or father. Because we include variables for family type (described below), we interpret the parental characteristics variables as interactions between the indicated characteristic and having a foreign father (mother). Standard errors are clustered based on the parents' birthplace and the years of the Census used to match parents with second generation respondents. Suppose, for example that the mother was born in Mexico, and the Censuses used for computing her characteristics are 1970 and 1980. Then this country-Census combination would form one cluster. If the mother was born in the United States, we use the father's birth country and Census years.

In the results presented below, the vector $X$ generally includes all three types of immigrant behavior for which we have measures—schooling, fertility, and labor supply—or what we term the "full specification." This specification may be appropriate in that it reduces the likelihood of spurious correlation. So, for example, a positive association between first- and second-generation fertility might be due to lower education levels of women in both generations rather than to intergenerational transmission of fertility per se. On the other hand, immigrant

\footnotetext{
${ }^{17}$ Note that these studies do include extensive controls for the respondent's individual characteristics.
} 
fertility (or plans for family size) may be the fundamental cause of immigrant schooling and immigrant labor supply levels. If so, including immigrant labor supply and schooling in the fertility equation could lead us to underestimate the full impact of immigrant fertility on the second generation. Therefore, we also present some results for the "matching specification," models with only the matching behavior on the right hand side (e.g., immigrant fertility in the second-generation fertility equation).

The vector $Z$ includes two dummy variables among the three possible parent combinations in our regression sample: (i) immigrant father and native mother and (ii) immigrant mother and native father (the omitted category is both parents immigrants); it also includes age, age squared, and year dummies. We do not include in our main specification the respondent's marital status, education or location variables. Part of the assimilation process involves children's marriage, education and location decisions; therefore, by excluding these variables, we are allowing the full effects of parental behavior to be observed. For example, more assimilated second-generation individuals may be less likely to live in ethnic enclaves. Nonetheless, since these channels are of interest, we also discuss some results with these controls. We also do not include controls for race and ethnicity. We believe that this is appropriate because race and ethnicity may be proxies for "regional" ethnic capital (for example the Latin American region). On the other hand, minority individuals may face discrimination or other barriers in labor markets or in education that could affect their decisions about schooling, fertility, or labor supply. Since minority immigrants tend to come from particular source country areas, failure to control for race and ethnicity could induce a spurious correlation between parental and child behavior that could instead be due to the common treatment in the United States of members of minority groups. Thus, we also discuss results from a model that includes 
race and ethnicity measured by dummies for black, non-Hispanic; Asian or Pacific Islander, nonHispanic; and Hispanic of any race (the omitted category is white non-Hispanic). ${ }^{18}$

Our main approach estimates equation (1) on the full sample of second generation women, which pools all second-generation family types. These yield the average effects of parental behavior. Later, we stratify by second-generation family type, another departure from earlier work. We also provide results for the three additional specifications, described earlier, designed to test whether our findings are consistent with a role for culture.

\section{B. Basic Regression Results}

Our basic results for the impact of parental generation behavior on second generation women’s outcomes are shown in Table 3, Panel A for all women and Panel B for married women. The table presents regression coefficients and hypothesis tests for two specifications. The matching specification examines the impact of only the matching parental characteristics on the dependent variable (e.g., fertility of immigrants from the mother's and father's source country on the respondent's fertility). The full specification includes measures of all three types of parental characteristics.

We first consider the results for all women beginning with parental education in columns (1) and (2). In both specifications there is strong evidence of intergenerational transmission of education, with stronger effects through immigrant fathers than immigrant mothers. In the matching models, both parental effects are significantly positive, but the coefficient on father's schooling (.29) is nearly twice as large as the coefficient on mother's schooling (.17). When additional parental variables are added, the coefficient on mother's schooling becomes small and insignificant, whereas the coefficient on father's schooling is not appreciably changed. In both specifications, the difference between the coefficients on father's and mother's education is

\footnotetext{
${ }^{18}$ A small number of non-Hispanic individuals of other races (0.46 per cent of the sample) were omitted.
} 
highly significant. The larger effect of father's education may be because it better captures the socio-economic status of the family than mother's education and it is the family's socioeconomic status that is the source of the intergenerational effect. As we have seen, this finding of a larger effect of fathers' than of mothers' education is consistent with the broader literature on intergenerational transmission of education.

The sum of the education effects for fathers and mothers is an estimate of the impact of one additional year of education for each parent in the first generation on the educational attainment of second-generation for women with both parents foreign born; this sum is highly significant in both specifications. The larger estimated transmission rate, .46 , is obtained for this sum in the matching specification (column 1). This effect implies that a three year difference in parental education between immigrants and natives, approximately the difference in schooling between native women and immigrant women from Latin America and the Caribbean in 2000 (see Tables 1 and 2) and almost twice the overall immigrant-native difference in Table 1, results in a second-generation difference of 1.4 years. ${ }^{19}$

When additional parental characteristics are added (Table 3a, column 2), an interesting finding that emerges is that higher levels of fertility of immigrant mothers lead to lower levels of second-generation education. Effects for the fertility of immigrant women from the father's source country are smaller in magnitude and insignificant, although the difference in coefficients for mothers and fathers is not significant. The negative impact of immigrant family size on second-generation education is consistent with a quality-quantity tradeoff in fertility (Becker 1991) and a comparison of the results for columns (1) and (2) suggests that a mechanism for intergenerational transmission of immigrant mother's education is through family size.

\footnotetext{
19 Our summed transmission effects in the matching specification for women and men (see Table 4 for men) of 0.45-0.46 are similar to the effects obtained by Card, DiNardo and Estes (2000) of about 0.4 for educational transmission, although they used information only on the father.
} 
The magnitude of the effect of parental generation family size on second generation education is large. To illustrate its magnitude, we computed the mean and standard deviation of the number of children of immigrant mothers aged 35-45 in the 1980 Census (an age group centered around the 40 year figure used to construct the parental generation explanatory variables and a Census year in which many of the immigrant parents would have been surveyed). We find that, among this group, fertility averaged 2.32 children with a standard deviation of 1.26. Since about half of our sample consists of second generation women both of whose parents were foreign born, it is of interest to estimate the impact of immigrant fertility for this group. When we add the mother's fertility effect to that for immigrant women from the father's country, we find that a one standard deviation increase in immigrant women's fertility from both the mother's and father's country lowers second-generation women and men's education by about 1.47 years. This is an economically important effect that is highly statistically significant. Previous research (Blau, Kahn and Papps 2011) has found falling immigrant fertility levels for recent cohorts, as fertility has been declining sharply around the world. If this lower level continues or further decreases occur, our results predict important increases in the education levels of second-generation immigrants.

Finally, there is some suggestive evidence of a positive effect of mother's working on education for women; however the effect of hours worked of women from the father's source country is negative, though not significant. Adding the employment effects for both parents leads to an insignificantly positive impact on schooling.

Turning now to the results for fertility in columns (3) and (4), we again find considerable evidence of intergenerational transmission. In the matching specification, the fertility of female immigrants from both the mother's and father's source countries significantly positively affects 
second-generation fertility. When we control for other parental characteristics, the effect of mother's fertility remains significant but of decreased magnitude, while the effect of the fertility of women from the father's source country is greatly reduced and loses statistical significance. In both specifications, however, the sum of the effects of fertility from the mother's and father's source countries is highly significant. We also find that in both specifications mother's fertility has a stronger effect than the fertility of immigrant women from the father's source country, although the difference is not statistically significant in either specification. The reduction in the magnitude of the coefficients on fertility in the immigrant generation between the matching and full specification appears related to the inclusion of work hours of women from the mother's source county and years of schooling of men from the father's source country, both of which are negatively related to second generation fertility. The sum of the two fertility effects is considerably larger in the matching specification (.731) than in the full specification (.403).

Finally, we consider the results for annual work hours. We again see considerable evidence of intergenerational transmission in both specifications (columns 5 and 6), with statistically significant positive effects for the sum of the coefficients on work hours of mothers and women from the father's source country that are only slightly larger in the matching model (0.50) than in the full specification (.47). In addition, the impact of mother's labor supply behavior is larger than the effect of women from the father's source country, nearly significantly so in the full specification. The results also indicate a highly significant positive effect of years of schooling of men from the father's source country on second generation women's labor supply.

Returning to the magnitude of the labor supply transmission rates, Table 1 shows that immigrant women's labor supply fell relative to natives between 1980 and 2000. Specifically, in 
1980, evaluated at age 40, native women worked about 7 percent more than immigrants; by 2000, this had risen to 14 percent higher work hours for natives. ${ }^{20}$ Suppose instead that immigrant women had closed the work hour gap with natives over this period. To do so they would have had to work 213 additional hours in 2000. Our results suggest that this would raise (future) second-generation women's labor supply by 107 hours (using our transmission rate of about .5), or by about 10 percent of the 1497 hour mean for native women. Put differently, we expect the disparity in labor supply between immigrants and natives in 2000 to have only minor consequences for future second-generation women's relative labor supply.

Table 3b shows results for married women. They are very similar to those for the full sample of second generation women. Results for the intergenerational transmission of education are about the same for married women, although the quality-quantity tradeoff effect on education is somewhat larger for married women. In the full specification, the intergenerational transmission effect for fertility and labor supply is larger for married women, although this is not the case in the matching specification and the differences are not large for labor supply. These comparisons of married and all women are weakly consistent with more persistence of cultural norms among those who have married.

\section{Intergenerational Transmission and Culture}

Our findings for the impact of immigrant women’s labor supply on second-generation women's annual hours may be due to the impact of culture, i.e., the intergenerational transmission of women's roles, but they may alternatively be due to other unobservables, such as unmeasured human capital. In this section, we consider additional specifications designed to test whether our results are consistent with culture playing a role.

\footnotetext{
${ }^{20}$ Blau, Kahn and Papps (2011) show the native-immigrant labor supply gap increased 32 percent among married women.
} 
First, we examine results from estimating our basic specification on men. Arguably, gender-neutral parental characteristics would be expected to affect both sexes similarly, while those associated with gender roles should have a larger effect or women. Table 4a shows intergenerational transmission regressions for men for years of schooling, which plausibly fall in the first category, and annual hours, which plausibly fall in the second. The specifications are the same as for women. For years of schooling, as expected, we see a strikingly similar level and pattern of intergenerational transmission for men as for women, with positive intergenerational transmission and larger effects for men's than for women's education in the immigrant generation. We also find strong evidence consistent with a quality-quantity tradeoff. These findings are consistent with a pattern of intergenerational transmission that is not related to gender roles. The results for labor supply are somewhat ambiguous in that we do find a positive effect of the labor supply of women in the mother's generation on second-generation men in the matching specification. There are however three important differences in the results for women and men that suggest that at least part of the impact of labor supply of women in the immigrant generation for women reflects gender-specific cultural factors. One is that the transmission rate for men in the matching specification, 0.33 , is smaller than the transmission rate for women of 0.5. The second is that, in this specification, the impact of mother's labor supply is roughly the same as the effect of women from the father's source country, whereas for women the effect of mother's labor supply is larger, though the difference is not statistically significant—-this gender difference is suggestive of a "role model" effect for women. Third, and most importantly, in the full specification, the female labor supply coefficients and their sum become small and insignificant for men, while, for women, the transmission effects remain highly significant individually and summed. 
The inference that our results for males are supportive of the notion that intergenerational transmission of immigrant female labor supply is related to gender roles is reinforced by the results for women and men presented in Table 4b, which add variables measuring parental generation work hours of men from both the mother's and father's source countries. Our findings for educational transmission remain quite similar to those presented in Tables 3a and 4a, excluding these variables, although there is some evidence for both groups of a positive and significant effect of male work hours and their sum on second generation education. This may operate through the effect of male employment on the socio-economic status of the family. In strong contrast however, male work hours are insignificant, both individually and jointly, in the female hours regressions, but positive and significant, both individually and jointly, in the male regressions. For women, we continue to find positive and significant effects for the annual hours of women from the mother's and father's source countries and their sum, while these variables are insignificant in the male regression. The finding of an impact of immigrant male labor supply on second generation men's labor supply is intriguing; it may represent the transmission of unmeasured human capital or work orientation, or some combination of the two.

The contrasting findings for men and women in the labor supply transmission equations are consistent with female annual hours capturing cultural factors associated with gender roles of women. We also investigated fertility transmission for women including male labor supply in the immigrant generation as an explanatory variable. As in the case of annual hours, male labor supply was not significant and its inclusion did not affect the results for the other variables. Based on these findings and our interest in the transmission of female labor supply and fertility as two variables particularly related to gender roles, we focus our subsequent analyses on the transmission of these variables for second generation women and continue to employ the basic 
specification used in Table 3a.

Second, in Table 5, we present fertility and labor supply models for all women and for married women that control for the potentially endogenous variables of the individual's education and location of residence (i.e., state). The findings for the key variables are similar to Tables 3a and b. Evaluating the transmission coefficients as the sum of the coefficients for mother's and father's parental characteristics, we find that the transmission coefficients reported in Table 5 are only slightly lower than those reported in Table 3a for all women and actually somewhat higher than those reported in Table 3b for married women.

Third, in Table 6, we look directly at the impact of source country characteristics on the fertility and labor supply behavior of second generation women in the United States. We report results for the fertility rate and the labor force participation rate ratio (women’s labor force participation rate divided by men's labor force participation rate) in the parental countries of origin. The regressions also control for source country GDP per capita and female primary and secondary enrollment rates, as well as the respondent’s age (quadratic), family type and year fixed effects. (See the Appendix and Blau, Kahn and Papps 2011 for more information about the source country variables.) As in the case of our analysis of parental characteristics, respondents are matched to source country characteristics at the time they are 10 years old. For number of children, when the labor force participation rate ratio is not included, we find a statistically significant positive effect of fertility rates in the mother's source country on second generation women; the sum of the coefficients on fertility in the mother's and father's source country is also positive and significant. When the labor force participation rate ratio, which has a significantly negative effect on fertility, is included, however, the coefficient on mother's source country fertility is reduced and is no longer significant, nor is the sum of coefficients on the mother's and 
father's source country fertility rate. For annual hours, the coefficient on the labor force participation rate ratio from the mother's source country is positive and significant in both specifications, as is the sum of the coefficients on mother's and father's source country activity ratios. This is suggestive evidence that source country characteristics do indeed influence the behavior of second generation immigrants. We note too, that there is stronger evidence of source country effects for both variables for mother's than for father's source country, although the differences are not significant. ${ }^{21}$

\section{Results by Family Type}

The regression results presented above pool all family types, and may be interpreted as representing the overall average effects of the parental variables. However it is also of interest to explore these relationships within each family type. Thus, in Tables 7, we present results for fertility (Panel A) and labor supply (Panel B) in the matching and full specification separately by family type: both parents immigrants (both parents); mother only immigrant (mother only); and father only immigrant (father only). Before discussing the results we note that, in the specification that is limited to both parents foreign born, there is a very high correlation between the mother and father variables that measure the same characteristic (i.e., education, fertility, and labor supply) due to the very high proportion of such families (87 percent) in which both mother and father come from the same source country (see Table A1). ${ }^{22}$ This is particularly problematic in the full specification, where we thus focus our discussion the sum of the mother's and father's coefficients.

\footnotetext{
${ }^{21}$ We also examined the impact of contemporary (2000) source country characteristics on these outcomes. We found statistically significant positive effects for both mother's and father's activity rate ratios on respondent's annual hours, and for their sum. The effects of mother's and father's source country fertility were positive, but not statistically significant; the sum of the coefficients on these variables was also insignificant.

${ }^{22}$ Specifically, for second generation women with both parents foreign born, the correlation between mom_f_edn and dad_m_edn is .924; between mom_f_nchild and dad_f_nchild .942; and between mom_f_hours and dad_f_hours .956.
} 
Looking first at the matching specification, the results are broadly consistent with those we presented earlier. We see statistically significant evidence of positive transmission of fertility and labor supply for all family types, with the mother's and father's coefficients all individually significant, and, for the both parent immigrant family type, their sum is significant as well. In addition, for both dependent variables, the sum of mother's and father's coefficients in the both parent immigrant family type is greater than the corresponding coefficients for mother only and father only families. So, for example, the fertility transmission effect in families where both parents are immigrants is .688 $(=.389+.299)$ compared to .475 for mother only families and .444 for father only families, with the former difference significant at the $10 \%$ level, although the latter is not statistically significant. Similarly, the labor supply transmission effect in families where both parents are immigrants is .542 compared to .188 for mother only families and .255 for father only families, with both differences highly statistically significant. This accords with the intuitive notion that the "treatment" is stronger in families where both parents are immigrants than in families where just one parent is foreign born. Finally, there is some evidence for a stronger effect of mothers' than of fathers' characteristics on second generation women for fertility: in families where both parents are immigrants, the coefficient on mother's fertility is larger than the coefficient on the fertility of women from the father's source country (although not significantly so), and the coefficient on immigrant generation fertility is somewhat higher in mother only than in father only families (although again the difference is not significant). However, in the labor supply regressions there is no evidence of larger transmission from mothers than fathers.

Moving on to the full specification, for fertility, we find evidence of positive transmission of number of children in the immigrant generation to the second generation for all three family 
types, although among women with both parents foreign-born, the sum of the parental fertility effects (.233) is significant at only the 12 percent level. In line with our previous results, we find that the transmission of fertility is stronger for the mother-only than for the father-only families, although not significantly so. In fact, the transmission effect is larger for the mother-only and the father-only families than it is for those with both parents foreign-born (i.e., the sum of the effects for women from the mother's and father's source countries), although these differences are not statistically significant. For labor supply, in the both-parent sample, we find statistically significant evidence of positive transmission of labor supply from women from the mothers' and the fathers' source countries (the sum) on second generation labor supply, with a fairly substantial transmission rate (0.59). However, in the mother-only and father-only foreign born samples, we find no evidence of an effect of the labor supply of mothers or of women from the fathers' source country on the labor supply of second-generation women. The differences in the transmission effects between the both parent and other two family types are highly significant. Thus, in the case of labor supply, both the matching and full specifications suggest that having two immigrant parents is a stronger treatment than having only one.

\section{E. Alternative Specifications}

We attempted several types of robustness checks for our basic sample of all second generation women. First, we experimented with the age at which second generation respondents in the CPS were matched to their immigrant generation parents in the Census, changing the age from 10 to 14. The results were similar to the findings shown in Table 3a. Second, we estimated models including controls for race and ethnicity, again obtaining results that were similar to our basic findings.

Third, our basic results may reflect the impact of parental generation control variables, 
however, alternatively they could be due to unmeasured country-specific factors that are correlated with these variables. To probe this issue further, in one specification, we included mother's and father's country dummies (recall there are 69 source countries), in effect relying on within-country variation in parental behavior to identify intergenerational transmission effects. While we continue to obtain positive and significant transmission of mother's generation work hours in the labor supply regression, the schooling and fertility results are weaker and even in instances wrong-signed. This suggests that there is insufficient variation within countries to successfully identify such effects and that between-country variation in parental fertility and education is what drives second generation education and fertility decisions. On the other hand, in another specification, we included mother's and father's dummies for five regions: i) Europe, Canada, New Zealand and Australia; ii) Asia, except the Middle East; iii) Latin America and the Caribbean region; iv) Sub-Saharan Africa; v) Middle East, including North Africa. The results for each of the parental characteristics in this specification were qualitatively similar to those in Table 3a. Evidently, within regions, there is enough variation across countries to identify the key transmission effects from the parents' to the children's generation. These results give us more confidence that our basic results do not reflect the impact of unmeasured factors, at least at the regional level.

\section{Conclusions}

In this paper, we have studied the transmission of first generation immigrant women's education, fertility, and labor supply behavior to the second generation, defined as US-born women with at least one foreign-born parent. Our research design used the March Current 
Population Surveys (CPS) from 1995 to 2011, which contain information on each woman’s country of birth and the country of birth of each of her parents. We then used Census data from 1970, 1980, 1990 or 2000 to attach information on labor supply, fertility and schooling of immigrants from the relevant source country(ies) when the second generation respondent was 10 years old. Using this information on immigrants as explanatory variables, we estimated regression models of the schooling, fertility, and labor supply of second-generation women.

Overall, we found that second-generation women's education, fertility and labor supply are significantly positively affected by the immigrant generation's levels of these variables, with the effect of mother's source country fertility and labor supply generally larger than that of women from the father's source country and the effect of the education of men from the father's source country larger than that of women from the mother's source country. Moreover, secondgeneration women's schooling levels are negatively affected by immigrant mother's fertility, suggesting a quality-quantity tradeoff for immigrant families.

We present a number of pieces of evidence that suggest our findings for fertility and labor supply are due at least in part to intergenerational transmission of gender roles, rather than other unobservables. First, for education and labor supply, we compare our female results to analogous results for men. For immigrant generation education, a plausibly gender neutral variable, we find strikingly similar results for second-generation men and women. For immigrant women's labor supply, a potentially gender-linked variable, we find evidence of a stronger effect on labor supply for second-generation women than for second-generation men, and for immigrant men's labor supply we find evidence of an effect on second-generation men's labor supply and no evidence of such an effect for second-generation women. Second, we expand our basic specification, which controls only for parental generation characteristics and 
respondent's age (as well as CPS survey year), to include controls for other individual respondent's characteristics like education, location and marital status. We continue to find strong, statistically significant evidence of the parental characteristics variables, suggestive evidence that these variables do affect individual preferences. Finally, we find statistically significant evidence of the impact of source country characteristics (rather than the characteristics of parental generation immigrants) on second generation behavior. This more directly tests the hypothesis that source country characteristics influence the behavior of second generation immigrants in the United States.

While our results suggest an important role for intergenerational transmission, they also indicate considerable convergence of immigrants to native levels of schooling, fertility, and labor supply across generations. In our "full” specification, which controls for all parental characteristics simultaneously, we find intergenerational transmission rates for those with both parents foreign born of 0.30 for education, 0.40 for fertility, and 0.47 for work hours. At these transmission rates, half or more of any difference in the immigrant generation has been eliminated by the second generation. Moreover, since the fertility of immigrant women is rapidly falling relative to natives in the most recent immigrant cohorts due to world-wide fertility declines (Blau, Kahn and Papps 2011), little future excess fertility in the second generation is anticipated. And, even though immigrant women's labor supply has decreased relative to natives, our relatively low estimates of intergenerational transmission suggest that this reduction will not have major consequences for the second and subsequent generations of the future. 


\section{Data Appendix}

Immigrant parent characteristics by source country are estimated using the 1970, 1980, 1990, and 2000 Census public use microdata samples obtained from the Integrated Public Use Microdata Series. The 1970 data is a combination of the 1 percent Form 1 state sample, the 1 percent Form 1 metropolitan area sample, the Form 2 state sample, and the Form 2 metropolitan area sample; the 1980, 1990, and 2000 data are the 5 percent state samples. We take a 1 percent random sample of households where all members are white and native-born and retain the full sample of all other respondents. Means of parent characteristics for each source country and Census year are adjusted to age 40 based on a model including source country fixed effects, age, age squared, the interaction of immigrant and age, and the interaction of immigrant and age squared. The regression sample for mothers (fathers) consists of women (men) between ages 18 and 64, excluding people of other race, with an allocated source country, or from a country that does not correspond to the set of countries available in the CPS. ${ }^{23}$

Second-generation immigrants in the CPS are matched to their immigrant "parents" in the Census by source country based on the year when the respondent was 10 years old. If this year is exactly a Census year $(1970,1980,1990$, or 2000), we use data from that Census. If it is an interior year, we use linear interpolation to compute a weighted average between the two nearest Censuses. For example, if the respondent was 10 years old in 1984, the parent characteristics would be a weighted average of the estimates from 1980 (.6 weight) and 1990 (.4 weight). If the respondent was 10 years old before 1970, we use immigrant parent characteristics from 1970. Since we use an age range of 25-49 for our second generation sample, every respondent turned 10 years old before 2000 .

The source of the source country variables used in Table 7 were: fertility: total fertility rate from United Nations Statistics Division, Series 13700 (2006); GDP per capita: GDP data from World Bank, World Development Indicators, accessed May 16th, 2007, population data from United Nations Population Division, Annual Estimates and Projections, accessed May 16, 2007; female/male labor force participation rate: economic activity rate for ages 15 and up from United Nations Statistics Division, Series 4270 and 4230 (2006); and primary and secondary female school enrollment rates from World Bank World Development Indicators CD-Rom, Series SE.PRM.ENRR.FE (2002). GDP per capita was collected annually, the remaining variables were collected at five or ten year intervals and interpolated annually; see also Blau, Kahn, and Papps (2011).

\footnotetext{
${ }^{23}$ The 1994 CPS is not included because fewer source countries are listed than in later years. U.S. citizens who were born abroad to native parents are not included since they may have lived abroad during their formative years.
} 


\section{References}

Alesina, Alberto F., Paola Giuliano, and Nathan Nunn, "On the Origins of Gender Roles: Women and the Plough,” NBER Working Paper No. 17098 (May 2011).

Antecol, Heather, “An Examination of Cross-Country Differences in the Gender Gap in Labor Force Participation Rates,” Labour Economics 7, no. 4 (July 2000): 409-426.

Bauer, Philipp and Regina T. Riphahn, "Heterogeneity in the Intergenerational Transmission of Educational Attainment: Evidence from Switzerland on Natives and Second-Generation Immigrants,” Journal of Population Economics 20, No. 1 (February 2007): 121-148.

Becker, Gary S., A Treatise on the Family (Cambridge MA: Harvard University Press, 1991).

Black, Sandra E and Paul Devereux, "Recent Developments in Intergenerational Mobility,” in Orley Ashenfelter and David Card, eds., Handbook of Labor Economics, vol. 4b (Amsterdam: North Holland Press, 2010), Ch. 16, pp. 1487-1541.

Blau, Francine D., "The Fertility of Immigrant Women: Evidence from High-Fertility Source Countries," in George J. Borjas and Richard B. Freeman, eds., Immigration and the Work Force: Economic Consequences for the United States and Source Areas (Chicago, IL: University of Chicago Press, 1992), pp. 93-133.

Blau, Francine D., Marianne A. Ferber, and Anne E. Winkler, The Economics of Women, Men, and Work, $6^{\text {th }}$ ed. (Upper Saddle River, N.J.: Pearson Education, 2010).

Blau, Francine D. and Lawrence M. Kahn, "Gender and Assimilation among Mexican Americans,” in George J. Borjas, ed., Mexican Immigration to the United States (Chicago: University of Chicago Press, 2007), pp. 57-106.

Blau, Francine D. and Lawrence M. Kahn, "Substitution Between Individual and Cultural Capital: Pre-Migration Labor Supply, Culture and US Labor Market Outcomes Among Immigrant Women,” NBER Working Paper No. 17275 (August 2011).

Blau, Francine D., Lawrence M. Kahn and Kerry L. Papps, “Gender, Source Country Characteristics and Labor Market Assimilation Among Immigrants: 1980-2000,” Review of Economics and Statistics 93, No. 1 (February 2011): 43-58.

Borjas, George J., “The Intergenerational Mobility of Immigrants,” Journal of Labor Economics 11, No. 1 (January 1993): 113-135.

Card, David, John DiNardo and Eugena Estes, "The More Things Change: Immigrants and the Children of Immigrants in the 1940s, the 1970s, and the 1990s,” in George J. Borjas, ed., Issues in the Economics of Immigration (Chicago: University of Chicago Press, 2000), pp. 227-269. 
Chiswick, Barry R, "Differences in Education and Earnings across Racial and Ethnic Groups:Tastes, Discriminationation, and Investments in Child Quality,” Quarterly Journal of Economics 103, No. 3 (August 1988): 571-97.

Duncan, Brian and Stephen J. Trejo, "Ethnic Identification, Intermarriage, and Unmeasured Progress by Mexican Americans,” in George J. Borjas, ed., Mexican Immigration to the United States (Chicago: University of Chicago Press, 2007), pp. 229-267.

Fernández, Raquel , "Culture and Economics," in the New Palgrave Dictionary of Economics, 2nd edition, edited by Steven N. Durlauf and Lawrence E. Blume (Basingstoke and New York: Palgrave Macmillan, 2008), pp. 333-340.

Fernández, Raquel and Alessandra Fogli, Culture: An Empirical Investigation of Beliefs, Work, and Fertility,” NBER Working Paper 11268 (April 2005).

Fernández, Raquel and Alessandra Fogli, "Fertility: The Role of Culture and Family Experience,” Journal of the European Economic Association 4, Nos. 2-3 (April-May 2006): 552-561.

Fernández, Racquel and Alessandra Fogli, "Culture: An Empirical Investigation of Beliefs, Work, and Fertility,” American Economic Journal: Macroeconomics 1 (January 2009): 146-177.

Fortuny, Karina, “Children of Immigrants: 2008 State Trends Update,” The Urban Institute, Brief 17, September 2010.

Gang, Ira N. and Klaus F. Zimmermann, "Is Child like Parent? Educational Attainment and Ethnic Origin,” Journal of Human Resources 35, No. 3 (Summer 2000): 550-569.

Jaeger, David A., “Reconciling the Old and New Census Bureau Education Questions: Recommendations for Researchers,” Journal of Business \& Economic Statistics 15, issue 3 (July 1997): 300-309.

Pronzato, Chiara, “An Examination of Paternal and Maternal Intergenerational Transmission of Schooling,” Journal of Population Economics 25, no. 2 (January 2012): 591-608.

van Ours, Jan C. and Justus Veenman, "The Educational Attainment of Second-Generation Immigrants in the Netherlands," Journal of Population Economics 16, No. 4 (November 2003): 739-753. 
Table 1: Age Adjusted Means for Immigrant, Native and Second Generation Women (Evaluated at Age 40)

\begin{tabular}{lccc}
\hline \hline & & & $\begin{array}{c}\text { Second } \\
\text { Generation }\end{array}$ \\
Variable & Natives & $\begin{array}{c}\text { Immigrants } \\
\text { Immigrants }\end{array}$ \\
\hline $\mathbf{1 9 8 0}^{\mathbf{a}}$ & & & \\
Years of Schooling & 12.4 & 11.0 & -- \\
Number of Children & 1.68 & 1.82 & -- \\
Annual Work Hours (including 0's) & 1025.2 & 950.7 & -- \\
& & & 13.8 \\
$\mathbf{2 0 0 0}$ & & & 1.33 \\
Years of Schooling & 13.6 & 11.9 & 1518.2 \\
Number of Children & 1.36 & 1.57 & \\
Annual Work Hours (including 0's) & 1496.6 & 1283.2 & \\
& & & \\
\hline
\end{tabular}

${ }^{a}$ Based on 1980 Census data. Age adjusted based on separate native and immigrant regressions that include age, and age squared, evaluated for 40 year olds.

${ }^{\mathrm{b}}$ Based on 1995-2011 CPS data. Age adjusted based on separate regressions for each column, that include age, age squared, and year fixed effects, evaluated for 40 year olds in 2000 . CPS sampling weights are employed in the regressions, adjusted so that each year receives equal weight.

Note: Census and CPS samples consist of women age 25 to 49, excluding those with allocated or unmatched birthplace; natives are US-born; immigrants are foreign-born; second-generation immigrants are US-born with at least one immigrant parent. See the text and other table notes for additional information on the CPS sample. 
Table 2: Age Adjusted Means for Immigrant, Native and Second Generation Women by Region (Evaluated at Age 40)

\begin{tabular}{lccc} 
& & & Second \\
& Immigrants & Immigrants & Generation \\
& 1980 & 2000 & 2000 \\
\hline Europe and Canada & & & \\
Years of Schooling & 11.9 & 13.9 & 14.2 \\
Number of Children & 1.65 & 1.31 & 1.27 \\
Annual Work Hours & 913.2 & $1,382.0$ & $1,490.4$ \\
& & & \\
Latin America and the Caribbean & & \\
Years of Schooling & 9.2 & 10.4 & 13.0 \\
Number of Children & 2.03 & 1.71 & 1.47 \\
Annual Work Hours & 886.7 & $1,210.9$ & $1,497.5$ \\
& & & \\
Asia & & & \\
Years of Schooling & 12.9 & 13.7 & 15.0 \\
Number of Children & 1.76 & 1.40 & 1.05 \\
Annual Work Hours & $1,155.0$ & $1,405.4$ & $1,695.7$ \\
\hline
\end{tabular}

Notes: For the second generation, respondents are included in the region if either parent immigrated from a country in that region. Means for immigrants are based on the respondent's own source country. Means are calculated in a similar manner as Table 1, just restricted by region. 
Table 3: Results for the Effect of Immigrant Parent Characteristics on Second Generation Education,Fertility, and Annual Hours (All Women and Married Women)

\begin{tabular}{|c|c|c|c|c|c|c|}
\hline & \multicolumn{2}{|c|}{ Years of Schooling } & \multicolumn{2}{|c|}{ Number of Children } & \multicolumn{2}{|c|}{ Annual Hours } \\
\hline & $(1)$ & $(2)$ & $(3)$ & $(4)$ & $(5)$ & $(6)$ \\
\hline \multicolumn{7}{|l|}{ A. All Women } \\
\hline \multicolumn{7}{|l|}{ Mother's Source Country: } \\
\hline Female Number of Children (mom_f_nchild) & & $\begin{array}{r}-0.908 * * * \\
(0.251)\end{array}$ & $\begin{array}{r}0.428^{* * *} \\
(0.065)\end{array}$ & $\begin{array}{r}0.324 * * \\
(0.132)\end{array}$ & & $\begin{array}{r}-27.652 \\
(81.023)\end{array}$ \\
\hline Female Years of Schooling (mom_f_edn) & $\begin{array}{r}0.168^{* * *} \\
(0.016)\end{array}$ & $\begin{array}{r}0.031 \\
(0.035)\end{array}$ & & $\begin{array}{r}0.013 \\
(0.016)\end{array}$ & & $\begin{array}{r}-9.163 \\
(9.657)\end{array}$ \\
\hline Female Annual Work Hours (00s) (mom_f_hours) & & $\begin{array}{l}0.050^{*} \\
(0.030)\end{array}$ & & $\begin{array}{r}-0.035^{* * *} \\
(0.013)\end{array}$ & $\begin{array}{r}0.305^{* * *} \\
(0.056)\end{array}$ & $\begin{array}{r}0.314^{* * *} \\
(0.077)\end{array}$ \\
\hline \multicolumn{7}{|l|}{ Father's Source Country: } \\
\hline Female Number of Children (dad_f_nchild) & & $\begin{array}{r}-0.258 \\
(0.350)\end{array}$ & $\begin{array}{r}0.303^{* * *} \\
(0.094)\end{array}$ & $\begin{array}{r}0.079 \\
(0.130)\end{array}$ & & $\begin{array}{r}88.788 \\
(67.338)\end{array}$ \\
\hline Male Years of Schooling (dad_m_edn) & $\begin{array}{r}0.287^{* * *} \\
(0.018)\end{array}$ & $\begin{array}{r}0.265^{* * *} \\
(0.033)\end{array}$ & & $\begin{array}{r}-0.041 * * * \\
(0.014)\end{array}$ & & $\begin{array}{r}22.582^{* * * *} \\
(7.690)\end{array}$ \\
\hline Female Annual Work Hours (00s) (dad_f_hours) & & $\begin{array}{r}-0.016 \\
(0.038)\end{array}$ & & $\begin{array}{r}0.005 \\
(0.014)\end{array}$ & $\begin{array}{r}0.193^{* * *} \\
(0.048)\end{array}$ & $\begin{array}{r}0.157^{* *} \\
(0.063)\end{array}$ \\
\hline r squared & 0.122 & 0.128 & 0.091 & 0.093 & 0.007 & 0.008 \\
\hline $\mathrm{N}$ & 34,141 & 34,141 & 34,141 & 34,141 & 34,141 & 34,141 \\
\hline p(mom_f_nchild-dad_f_nchild=0) & & 0.165 & 0.353 & 0.254 & & 0.279 \\
\hline p(mom_f_nchild+dad_f_nchild=0) & & 0.003 & 0.000 & 0.008 & & 0.554 \\
\hline p(mom_f_edn-dad_m_edn $=0)$ & 0.000 & 0.000 & & 0.033 & & 0.014 \\
\hline$p($ mom_f_edn+dad_m_edn=0) & 0.000 & 0.000 & & 0.104 & & 0.257 \\
\hline$p($ mom_f_hours - dad_f_hours $=0)$ & & 0.116 & & 0.026 & 0.142 & 0.122 \\
\hline$p\left(\right.$ mom_f_hours $+d a d \_f$ hours $\left.=0\right)$ & & 0.533 & & 0.006 & 0.000 & 0.000 \\
\hline \multicolumn{7}{|l|}{ B. Married Women } \\
\hline \multicolumn{7}{|l|}{ Mother's Source Country: } \\
\hline Female Number of Children (mom_f_nchild) & & $\begin{array}{r}-1.094^{* * *} \\
(0.246)\end{array}$ & $\begin{array}{r}0.392^{* * *} \\
(0.075)\end{array}$ & $\begin{array}{r}0.413^{* * *} \\
(0.153)\end{array}$ & & $\begin{array}{r}-24.826 \\
(105.369)\end{array}$ \\
\hline Female Years of Schooling (mom_f_edn) & $\begin{array}{r}0.177^{* * *} \\
(0.020)\end{array}$ & $\begin{array}{r}0.023 \\
(0.034)\end{array}$ & & $\begin{array}{r}0.027 \\
(0.019)\end{array}$ & & $\begin{array}{r}-17.966 \\
(13.418)\end{array}$ \\
\hline Female Annual Work Hours (00s) (mom_f_hours) & & $\begin{array}{l}0.050^{*} \\
(0.028)\end{array}$ & & $\begin{array}{r}-0.027^{* *} \\
(0.014)\end{array}$ & $\begin{array}{r}0.275^{* * *} \\
(0.078)\end{array}$ & $\begin{array}{r}0.353^{* * *} \\
(0.094)\end{array}$ \\
\hline \multicolumn{7}{|l|}{ Father's Source Country: } \\
\hline Female Number of Children (dad_f_nchild) & & $\begin{array}{r}-0.278 \\
(0.310)\end{array}$ & $\begin{array}{r}0.250^{* * *} \\
(0.091)\end{array}$ & $\begin{array}{r}0.146 \\
(0.139)\end{array}$ & & $\begin{array}{l}133.419 \\
(97.715)\end{array}$ \\
\hline Male Years of Schooling (dad_m_edn) & $\begin{array}{r}0.288^{* * *} \\
(0.020)\end{array}$ & $\begin{array}{r}0.268^{* * *} \\
(0.031)\end{array}$ & & $\begin{array}{l}-0.028^{*} \\
(0.017)\end{array}$ & & $\begin{array}{r}21.827^{* *} \\
(10.673)\end{array}$ \\
\hline Female Annual Work Hours (00s) (dad_f_hours) & & $\begin{array}{r}-0.033 \\
(0.034)\end{array}$ & & $\begin{array}{r}0.015 \\
(0.014)\end{array}$ & $\begin{array}{r}0.149 * * \\
(0.070)\end{array}$ & $\begin{array}{c}0.177^{*} \\
(0.102)\end{array}$ \\
\hline r squared & 0.139 & 0.146 & 0.100 & 0.101 & 0.005 & 0.006 \\
\hline $\mathrm{N}$ & 19,870 & 19,870 & 19,870 & 19,870 & 19,870 & 19,870 \\
\hline p(mom_f_nchild-dad_f_nchild=0) & & 0.063 & 0.320 & 0.267 & & 0.299 \\
\hline$p($ mom_f_nchild+dad_f_nchild=0) & & 0.000 & 0.000 & 0.001 & & 0.421 \\
\hline p(mom_f_edn-dad_m_edn=0) & 0.000 & 0.000 & & 0.060 & & 0.028 \\
\hline$p($ mom_f_edn+dad_m_edn $=0)$ & 0.000 & 0.000 & & 0.947 & & 0.812 \\
\hline$p($ mom_f_hours - dad_f_hours $=0)$ & & 0.062 & & 0.035 & 0.216 & 0.196 \\
\hline$p$ (mom_f_hours + dad_f_hours $=0)$ & & 0.709 & & 0.046 & 0.000 & 0.000 \\
\hline
\end{tabular}

Source: 1995-2011 March CPS and 1970, 1980, 1990, and 2000 Censuses.

Notes: ${ }^{*} p<.10,{ }^{* *} p<.05,{ }^{* * *} p<.01$. Standard errors are clustered by parent's source country (mother then father) crossed with which census(es) provided the data. The sample consists of women age 25-49 excluding those with allocated or unmatched birthplace, allocated or unmatched parent birthplace, and those of other race. Regressions are weighted using CPS sampling weights adjusted so that each year receives equal weight. Regressions include controls for age (quadratic), family type, and year fixed effects. 
Table 4a: Results for the Effect of Immigrant Parent Characteristics on Second Generation Education and Annual Hours (All Second-Generation Men)

\begin{tabular}{|c|c|c|c|c|}
\hline & \multicolumn{2}{|c|}{ Years of Schooling } & \multicolumn{2}{|c|}{ Annual Hours } \\
\hline & $(1)$ & $(2)$ & $(5)$ & $(6)$ \\
\hline \multicolumn{5}{|l|}{ Mother's Source Country: } \\
\hline \multirow[t]{2}{*}{ Female Number of Children (mom_f_nchild) } & & $-1.222 * * *$ & & $-166.278 * *$ \\
\hline & & $(0.248)$ & & $(81.106)$ \\
\hline \multirow[t]{2}{*}{ Female Years of Schooling (mom_f_edn) } & $0.146 * * *$ & 0.005 & & 1.118 \\
\hline & $(0.021)$ & $(0.033)$ & & $(10.431)$ \\
\hline \multirow[t]{2}{*}{ Female Annual Work Hours (00s) (mom_f_hours) } & & -0.003 & $0.194^{* *}$ & -0.007 \\
\hline & & $(0.029)$ & $(0.080)$ & $(0.084)$ \\
\hline \multicolumn{5}{|l|}{ Father's Source Country: } \\
\hline \multirow[t]{2}{*}{ Female Number of Children (dad_f_nchild) } & & 0.146 & & 11.318 \\
\hline & & $(0.350)$ & & $(88.165)$ \\
\hline \multirow[t]{2}{*}{ Male Years of Schooling (dad_m_edn) } & $0.302 * * *$ & $0.302 * * *$ & & 10.319 \\
\hline & $(0.020)$ & $(0.032)$ & & $(8.086)$ \\
\hline \multirow[t]{2}{*}{ Female Annual Work Hours (00s) (dad_f_hours) } & & 0.027 & $0.132 *$ & 0.055 \\
\hline & & $(0.036)$ & $(0.074)$ & $(0.094)$ \\
\hline r squared & 0.121 & 0.126 & 0.034 & 0.037 \\
\hline $\mathrm{N}$ & 31,160 & 31,160 & 31,160 & 31,160 \\
\hline p(mom_f_nchild-dad_f_nchild=0) & & 0.002 & & 0.210 \\
\hline p(mom_f_nchild+dad_f_nchild $=0)$ & & 0.011 & & 0.097 \\
\hline p(mom_f_edn-dad_m_edn=0) & 0.000 & 0.000 & & 0.542 \\
\hline p(mom_f_edn+dad_m_edn=0) & 0.000 & 0.000 & & 0.298 \\
\hline$p($ mom_f_hours-dad_f_hours $=0)$ & & 0.442 & 0.542 & 0.582 \\
\hline$p\left(\right.$ mom_f_hours $+d a d \_f$ hours $\left.=0\right)$ & & 0.645 & 0.005 & 0.725 \\
\hline
\end{tabular}

Source: 1995-2011 March CPS and 1970, 1980, 1990, and 2000 Censuses.

Notes: ${ }^{*} \mathrm{p}<.10, * * \mathrm{p}<.05, * * * \mathrm{p}<.01$. Standard errors are clustered by parent's source country (mother then father) crossed with which census(es) provided the data. The sample consists of women age 25-49 excluding those with allocated or unmatched birthplace, allocated or unmatched parent birthplace, and those of other race. Regressions are weighted using CPS sampling weights adjusted so that each year receives equal weight. Regressions include controls for age (quadratic), family type, and year fixed effects. 
Table 4b: Results for the Effect of Immigrant Parent Characteristics on Second Generation Education and Annual Hours, Adding Immigrant Generation Male Labor Supply (All Second-Generation Women and Men)

\begin{tabular}{|c|c|c|c|c|}
\hline & \multicolumn{2}{|c|}{ Years of Schooling } & \multicolumn{2}{|c|}{ Annual Hours } \\
\hline & (1) & $(2)$ & (3) & (4) \\
\hline & Women & Men & Women & Men \\
\hline \multicolumn{5}{|l|}{ Mother's Source Country: } \\
\hline \multirow[t]{2}{*}{ Female Number of Children (mom_f_nchild) } & $-0.929 * * *$ & $-1.250 * * *$ & -27.728 & $181.414^{* *}$ \\
\hline & $(0.239)$ & $(0.220)$ & $(81.191)$ & $(74.932)$ \\
\hline \multirow[t]{2}{*}{ Female Years of Schooling (mom_f_edn) } & 0.028 & -0.006 & -9.792 & -5.071 \\
\hline & $(0.034)$ & $(0.030)$ & $(10.047)$ & $(9.461)$ \\
\hline \multirow[t]{2}{*}{ Female Annual Work Hours (00s) (mom_f_hours) } & 0.037 & -0.019 & $0.323^{* * *}$ & -0.087 \\
\hline & $(0.027)$ & $(0.024)$ & $(0.078)$ & $(0.072)$ \\
\hline \multirow[t]{2}{*}{ Male Annual Work Hours (00s) (mom_m_hours) } & 0.038 & $0.079 * *$ & -0.006 & $0.405^{* * *}$ \\
\hline & $(0.031)$ & $(0.032)$ & $(0.082)$ & $(0.094)$ \\
\hline \multicolumn{5}{|l|}{ Father's Source Country: } \\
\hline \multirow[t]{2}{*}{ Female Number of Children (dad_f_nchild) } & -0.300 & 0.119 & 94.422 & 0.273 \\
\hline & $(0.309)$ & $(0.310)$ & $(67.126)$ & $(74.130)$ \\
\hline \multirow[t]{2}{*}{ Male Years of Schooling (dad_m_edn) } & $0.256 * * *$ & $0.295^{* * *}$ & $24.045^{* * *}$ & 7.840 \\
\hline & $(0.032)$ & $(0.032)$ & $(7.684)$ & $(7.588)$ \\
\hline \multirow[t]{2}{*}{ Female Annual Work Hours (00s) (dad_f_hours) } & -0.034 & 0.011 & $0.177^{* * *}$ & -0.018 \\
\hline & $(0.031)$ & $(0.030)$ & $(0.066)$ & $(0.077)$ \\
\hline \multirow[t]{2}{*}{ Male Annual Work Hours (00s) (dad_m_hours) } & $0.071 * *$ & $0.072 * *$ & -0.091 & $0.321 * * *$ \\
\hline & $(0.031)$ & $(0.028)$ & $(0.080)$ & $(0.080)$ \\
\hline r squared & 0.130 & 0.130 & 0.008 & 0.043 \\
\hline $\mathrm{N}$ & 34,141 & 31,160 & 34,141 & 31,160 \\
\hline p(mom_f_nchild-dad_f_nchild=0) & 0.163 & 0.001 & 0.258 & 0.166 \\
\hline p(mom_f_nchild+dad_f_nchild=0) & 0.000 & 0.001 & 0.516 & 0.011 \\
\hline p(mom_f_edn-dad_m_edn=0) & 0.000 & 0.000 & 0.012 & 0.370 \\
\hline p(mom_f_edn+dad_m_edn=0) & 0.000 & 0.000 & 0.231 & 0.767 \\
\hline p(mom_f_hours-dad_f_hours =0) & 0.089 & 0.443 & 0.152 & 0.547 \\
\hline p(mom_f_hours+dad_f_hours=0) & 0.929 & 0.826 & 0.000 & 0.270 \\
\hline p(mom_m_hours-dad_m_hours $=0)$ & 0.454 & 0.876 & 0.541 & 0.530 \\
\hline p(mom_m_hours+dad_m_hours $=0)$ & 0.013 & 0.000 & 0.244 & 0.000 \\
\hline
\end{tabular}

Source: 1995-2011 March CPS and 1970, 1980, 1990, and 2000 Censuses.

Notes: ${ }^{*} \mathrm{p}<.10, * * \mathrm{p}<.05, * * * \mathrm{p}<.01$. Standard errors are clustered by parent's source country (mother then father) crossed with which census(es) provided the data. The sample consists of women age 25-49 excluding those with allocated or unmatched birthplace, allocated or unmatched parent birthplace, and those of other race. Regressions are weighted using CPS sampling weights adjusted so that each year receives equal weight. Regressions include controls for age (quadratic), family type, and year fixed effects. 
Table 5: Results for the Effect of Immigrant Parent Characteristics on Second Generation Fertility and Annual Hours, Controlling for Respondent's Education and State Dummies (All Women and Married Women)

\begin{tabular}{|c|c|c|c|c|}
\hline & \multicolumn{2}{|c|}{ Number of Children } & \multicolumn{2}{|c|}{ Annual Hours } \\
\hline & All & Married & All & Married \\
\hline & $(1)$ & $(2)$ & (3) & (4) \\
\hline \multicolumn{5}{|l|}{ Mother's Source Country: } \\
\hline Female Number of Children (mom_f_nchild) & $\begin{array}{r}0.280^{* *} \\
(0.135)\end{array}$ & $\begin{array}{r}0.366^{* *} \\
(0.156)\end{array}$ & $\begin{array}{r}27.022 \\
(79.012)\end{array}$ & $\begin{array}{r}43.314 \\
(103.084)\end{array}$ \\
\hline Female Years of Schooling (mom_f_edn) & $\begin{array}{r}0.013 \\
(0.017)\end{array}$ & $\begin{array}{r}0.028 \\
(0.019)\end{array}$ & $\begin{array}{r}-13.726 \\
(9.956)\end{array}$ & $\begin{array}{r}-22.184^{*} \\
(13.350)\end{array}$ \\
\hline Female Annual Work Hours (00s) (mom_f_hours) & $\begin{array}{r}-0.030^{* *} \\
(0.012)\end{array}$ & $\begin{array}{l}-0.023^{*} \\
(0.013)\end{array}$ & $\begin{array}{r}0.245^{* * *} \\
(0.072)\end{array}$ & $\begin{array}{r}0.299 * * * \\
(0.090)\end{array}$ \\
\hline \multicolumn{5}{|l|}{ Father's Source Country: } \\
\hline Female Number of Children (dad_f_nchild) & $\begin{array}{r}0.092 \\
(0.118)\end{array}$ & $\begin{array}{r}0.135 \\
(0.138)\end{array}$ & $\begin{array}{r}99.595 \\
(69.107)\end{array}$ & $\begin{array}{r}181.510^{*} \\
(98.259)\end{array}$ \\
\hline Male Years of Schooling (dad_m_edn) & $\begin{array}{r}-0.026^{* *} \\
(0.012)\end{array}$ & $\begin{array}{l}-0.017 \\
(0.016)\end{array}$ & $\begin{array}{r}0.599 \\
(7.907)\end{array}$ & $\begin{array}{r}5.362 \\
(10.530)\end{array}$ \\
\hline Female Annual Work Hours (00s) (dad_f_hours) & $\begin{array}{r}0.008 \\
(0.013)\end{array}$ & $\begin{array}{r}0.018 \\
(0.014)\end{array}$ & $\begin{array}{r}0.142^{* *} \\
(0.072)\end{array}$ & $\begin{array}{c}0.190^{*} \\
(0.106)\end{array}$ \\
\hline Respondent's Years of Schooling (gradecomp) & $\begin{array}{r}-0.055^{* * *} \\
(0.012)\end{array}$ & $\begin{array}{r}-0.046^{* * *} \\
(0.013)\end{array}$ & $\begin{array}{r}83.850^{* * *} \\
(4.709)\end{array}$ & $\begin{array}{r}68.944 * * * \\
(6.342)\end{array}$ \\
\hline r squared & 0.111 & 0.114 & 0.054 & 0.037 \\
\hline $\mathrm{N}$ & 34,141 & 19,870 & 34,141 & 19,870 \\
\hline p(mom_f_nchild-dad_f_nchild=0) & 0.372 & 0.338 & 0.514 & 0.376 \\
\hline p(mom_f_nchild+dad_f_nchild=0) & 0.009 & 0.003 & 0.199 & 0.079 \\
\hline p(mom_f_edn-dad_m_edn=0) & 0.107 & 0.118 & 0.268 & 0.126 \\
\hline p(mom_f_edn+dad_m_edn=0) & 0.411 & 0.635 & 0.295 & 0.293 \\
\hline$p($ mom_f_hours-dad_f_hours $=0)$ & 0.029 & 0.042 & 0.319 & 0.441 \\
\hline$p\left(\right.$ mom_f hours $+d a d \_f$ hours $\left.=0\right)$ & 0.011 & 0.079 & 0.000 & 0.000 \\
\hline
\end{tabular}

Source: 1995-2011 March CPS and 1970, 1980, 1990, and 2000 Censuses.

Notes: ${ }^{*} p<.10,{ }^{* *} p<.05,{ }^{* * *} p<.01$. Standard errors are clustered by parent's source country (mother then father) crossed with which census(es) provided the data. The sample consists of married women age 25-49 excluding those with allocated or unmatched birthplace, allocated or unmatched parent birthplace, and those of other race. Regressions are weighted using CPS sampling weights adjusted so that each year receives equal weight. Regressions control for age (quadratic), family type, respondent's education, state dummies, and year fixed effects. 
Table 6: Results for the Effect of Immigrant Source Country Characteristics on Second Generation Fertility and Annual Hours (All Second-Generation Women)

\begin{tabular}{|c|c|c|c|c|}
\hline & \multicolumn{2}{|c|}{ Number of Children } & \multicolumn{2}{|c|}{ Annual Hours } \\
\hline & $(1)$ & $(2)$ & $(3)$ & $(4)$ \\
\hline \multicolumn{5}{|l|}{ Mother's Source Country: } \\
\hline \multirow[t]{2}{*}{ Fertility (mom_fert) } & $0.046^{*}$ & 0.016 & & 8.474 \\
\hline & $(0.024)$ & $(0.021)$ & & $(14.392)$ \\
\hline \multirow[t]{2}{*}{ Labor Force Participation Rate Ratio (mom_Ifpr_ratio) } & & $-0.597 * * *$ & $223.791 * *$ & $249.033^{* *}$ \\
\hline & & $(0.169)$ & $(105.795)$ & $(111.500)$ \\
\hline \multicolumn{5}{|l|}{ Father's Source Country: } \\
\hline \multirow[t]{2}{*}{ Fertility (dad_fert) } & 0.009 & 0.003 & & $17.857^{*}$ \\
\hline & $(0.021)$ & $(0.020)$ & & $(10.042)$ \\
\hline \multirow[t]{2}{*}{ Labor Force Participation Rate Ratio (dad_Ifpr_ratio) } & & -0.112 & 40.763 & 87.191 \\
\hline & & $(0.168)$ & $(84.811)$ & $(86.863)$ \\
\hline r squared & 0.082 & 0.084 & 0.005 & 0.005 \\
\hline $\mathrm{N}$ & 34,141 & 34,141 & 34,141 & 34,141 \\
\hline$p($ mom_fert-dad_fert $=0)$ & 0.267 & 0.679 & & 0.623 \\
\hline $\mathrm{p}\left(\mathrm{mom} \_f e r t+d a d \_f e r t=0\right)$ & 0.078 & 0.478 & & 0.098 \\
\hline p(mom_Ifpr_ratio-dad_Ifpr_ratio=0) & & 0.053 & 0.272 & 0.324 \\
\hline $\mathrm{p}(\mathrm{mom}$ _Ifpr_ratio+dad_Ifpr_ratio=0) & & 0.000 & 0.006 & 0.004 \\
\hline
\end{tabular}

Source: 1995-2011 March CPS and 1970, 1980, 1990, and 2000 Censuses.

Notes: ${ }^{*} p<.10, * * p<.05, * * * p<.01$. Standard errors are clustered by parent's source country (mother then father) crossed with which census(es) provided the data. The sample consists of women age 25-49 excluding those with allocated or unmatched birthplace, allocated or unmatched parent birthplace, and those of other race. Regressions are weighted using CPS sampling weights adjusted so that each year receives equal weight. Regressions control for age (quadratic), family type, and year fixed effects, and source country GDP per capita and primary and secondary female enrollment rates. 
Table 7: Effect of Immigrant Parent Characteristics on Second Generation Fertility and Annual Hours by Family Type (All Second-Generation Women)

\begin{tabular}{|c|c|c|c|c|c|c|}
\hline & $(1)$ & (2) & (3) & (4) & (5) & (6) \\
\hline \multicolumn{7}{|l|}{ A. Fertility } \\
\hline \multicolumn{7}{|l|}{ Mother's Source Country: } \\
\hline \multirow[t]{2}{*}{ Female Number of Children (mom_f_nchild) } & $0.389 * * *$ & $0.513^{* *}$ & $0.475^{* * *}$ & $0.540 * * *$ & & \\
\hline & $(0.134)$ & $(0.218)$ & (0.059) & $(0.166)$ & & \\
\hline \multirow[t]{2}{*}{ Female Years of Schooling (mom_f_edn) } & & $0.049^{*}$ & & 0.024 & & \\
\hline & & $(0.028)$ & & $(0.020)$ & & \\
\hline \multirow[t]{2}{*}{ Female Annual Work Hours (00s) (mom_f_hours) } & & -0.014 & & -0.024 & & \\
\hline & & (0.031) & & $(0.019)$ & & \\
\hline \multicolumn{7}{|l|}{ Father's Source Country: } \\
\hline \multirow[t]{2}{*}{ Female Number of Children (dad_f_nchild) } & $0.299 * *$ & -0.280 & & & $0.444^{* * *}$ & $0.422 * *$ \\
\hline & $(0.119)$ & $(0.212)$ & & & $(0.131)$ & $(0.165)$ \\
\hline \multirow[t]{2}{*}{ Male Years of Schooling (dad_m_edn) } & & $-0.083^{* * *}$ & & & & -0.008 \\
\hline & & $(0.023)$ & & & & $(0.017)$ \\
\hline \multirow[t]{2}{*}{ Female Annual Work Hours (00s) (dad_f_hours) } & & -0.031 & & & & 0.009 \\
\hline & & $(0.027)$ & & & & (0.019) \\
\hline r squared & 0.098 & 0.102 & 0.089 & 0.090 & 0.088 & 0.088 \\
\hline $\mathrm{N}$ & 16,563 & 16,563 & 8,934 & 8,934 & 8,644 & 8,644 \\
\hline Second-Generation Type & \multicolumn{2}{|c|}{ Both Parents } & \multicolumn{2}{|c|}{ Mother Only } & \multicolumn{2}{|c|}{ Father Only } \\
\hline$p($ mom_f_nchild+dad_f_nchild $=0)$ & \multirow[t]{3}{*}{0.000} & 0.122 & & & & \\
\hline p(mom_f_edn+dad_m_edn $=0)$ & & 0.053 & & & & \\
\hline$p($ mom_f_hours + dad_f_hours $=0)$ & & 0.064 & & & & \\
\hline \multicolumn{7}{|l|}{ B. Annual Hours } \\
\hline \multicolumn{7}{|l|}{ Mother's Source Country: } \\
\hline \multirow[t]{2}{*}{ Female Number of Children (mom_f_nchild) } & & 25.503 & & -95.573 & & \\
\hline & & $(167.424)$ & & $(105.246)$ & & \\
\hline \multirow[t]{2}{*}{ Female Years of Schooling (mom_f_edn) } & & -24.967 & & 1.356 & & \\
\hline & & $(16.666)$ & & $(13.705)$ & & \\
\hline \multirow[t]{2}{*}{ Female Annual Work Hours (00s) (mom_f_hours) } & $0.222 *$ & 0.348 & $0.188^{*}$ & 0.050 & & \\
\hline & $(0.131)$ & $(0.225)$ & $(0.100)$ & $(0.122)$ & & \\
\hline \multicolumn{7}{|l|}{ Father's Source Country: } \\
\hline \multirow[t]{2}{*}{ Female Number of Children (dad_f_nchild) } & & 57.468 & & & & 75.881 \\
\hline & & $(159.232)$ & & & & $(82.162)$ \\
\hline \multirow[t]{2}{*}{ Male Years of Schooling (dad_m_edn) } & & $31.479 * *$ & & & & $23.760 * *$ \\
\hline & & $(14.011)$ & & & & (9.315) \\
\hline \multirow[t]{2}{*}{ Female Annual Work Hours (00s) (dad_f_hours) } & $0.320 * *$ & 0.241 & & & $0.255^{* * *}$ & 0.156 \\
\hline & $(0.144)$ & $(0.220)$ & & & $(0.070)$ & $(0.110)$ \\
\hline r squared & 0.013 & 0.014 & 0.007 & 0.007 & 0.006 & 0.007 \\
\hline $\mathrm{N}$ & 16,563 & 16,563 & 8,934 & 8,934 & 8,644 & 8,644 \\
\hline Second-Generation Type & \multicolumn{2}{|c|}{ Both Parents } & \multicolumn{2}{|c|}{ Mother Only } & Father & Only \\
\hline p(mom_f_nchild+dad_f_nchild $=0)$ & & 0.424 & & & & \\
\hline$p($ mom_f_edn+dad_m_edn $=0)$ & & 0.611 & & & & \\
\hline $\mathrm{p}\left(\mathrm{mom} \_\mathrm{f}\right.$ hhours + dad_f $\mathrm{f}$ hours $\left.=0\right)$ & 0.000 & 0.000 & & & & \\
\hline
\end{tabular}

Source: 1995-2011 March CPS and 1970, 1980, 1990, and 2000 Censuses.

Notes: ${ }^{*} \mathrm{p}<.10,{ }^{* *} \mathrm{p}<.05,{ }^{* * *} \mathrm{p}<.01$. Standard errors are clustered by parent's source country (mother then father) crossed with which census(es) provided the data. The sample consists of women age 25-49 excluding those with allocated or unmatched birthplace, allocated or unmatched parent birthplace, and those of other race. Regressions are weighted using CPS sampling weights adjusted so that each year receives equal weight. Regressions include controls for age (quadratic) and year fixed effects. 
Table A1: Selected Means for Women and Men: Natives and Second-Generation Individuals, 1995-2011

\begin{tabular}{|c|c|c|c|c|}
\hline \multirow[b]{2}{*}{ Variable } & \multicolumn{2}{|c|}{ Women } & \multicolumn{2}{|c|}{ Men } \\
\hline & Natives & $\begin{array}{c}\text { Second } \\
\text { Generation } \\
\text { Immigrants }\end{array}$ & Natives & $\begin{array}{c}\text { Second } \\
\text { Generation } \\
\text { Immigrants }\end{array}$ \\
\hline Age & 37.47 & 35.90 & 37.44 & 35.70 \\
\hline Asian, non-Hispanic & 0.005 & 0.079 & 0.005 & 0.088 \\
\hline Black, non-Hispanic & 0.156 & 0.039 & 0.132 & 0.036 \\
\hline Hispanic & 0.039 & 0.383 & 0.039 & 0.382 \\
\hline White, non-Hispanic & 0.8 & 0.499 & 0.824 & 0.494 \\
\hline Married & 0.612 & 0.569 & 0.59 & 0.512 \\
\hline Number of Children & 1.115 & 1.118 & 0.836 & 0.760 \\
\hline Years of Schooling & 13.668 & 13.921 & 13.506 & 13.756 \\
\hline Annual Work Hours & 1456.295 & 1455.594 & 1985.242 & 1939.754 \\
\hline Imm Mother/Native Father & . & 0.264 & . & 0.267 \\
\hline Imm Father/Native Mother & . & 0.255 & . & 0.237 \\
\hline Both Parents Immigrants & . & 0.481 & . & 0.496 \\
\hline - from Different Source Countries & . & 0.128 & . & 0.125 \\
\hline - from Same Source Country & . & 0.872 & . & 0.875 \\
\hline Sample Size & 420,361 & 34,141 & 379,807 & 31,160 \\
\hline
\end{tabular}

Source: 1995-2011 March CPS.

Notes: The sample consists of individuals age 25-49 excluding those with allocated or unmatched birthplace, allocated or unmatched parent birthplace, and those of other race. Natives are US-born with both parents also US-born. Second Generation Immigrants are US-born with at least one parent foreign-born. Means are weighted using CPS sampling weights adjusted so that each year receives equal weight. 